\title{
Research on the Influence of Self-consciousness on College Students' Interpersonal Relationship
}

\author{
Zhimei Yang, Wen Li \\ Teaching Department of Ideological and Political Theory Course, Xi'an Peihua University, Xi'an \\ 710125, China
}

\begin{abstract}
With the rapid development of economy and the acceleration of social pace, college students are faced with challenges and pressures from all aspects; whose mental health problems have become increasingly acute, among them, the interpersonal relationship problem is the most serious, more and more researchers start paying close attention to college students' interpersonal relationship problems and seek solutions, this paper conducts empirical research on the influence of college students' self- consciousness on their interpersonal relationships, mainly find that both the inner self and the public self in self- consciousness have a strong predictive effect on the interpersonal relationship of college students.
\end{abstract}

Keywords: self- consciousness, college students, interpersonal relationship.

\section{Introduction}

Self-consciousness is called as self as well, which is an advanced stage in the development of individual consciousness. Self-consciousness is the core part of consciousness, which is the "selfcognition" or your own perception of yourself. It contains content related to self-evaluation, selfawareness and self-control. Researchers generally divide interpersonal relationships into broad interpersonal relationships and narrow interpersonal relationships; the broad interpersonal relationship refers to the sum of the relationships among all people in a given society, which it contains all aspects of the relationship among people [1][2][3]. Strictly speaking, the meaning of interpersonal communication in college students has broad sense and narrow sense. Broad interpersonal communication refers to the interaction process between college students and all people involved. Narrow interpersonal communication refers to the interaction and communication of individual or group involved with college students when college students in school, it is an interactive process among college students and between college students and others to communicate information, exchange ideas, express feelings and coordinate behaviors.

\section{Overall Situation of College Students' Interpersonal Relationship}

Generally speaking, according to the investigation situation of selected six universities in Xi'an, the overall situation of College Students' interpersonal relationship is relatively good, the average score is 11.07 explained by (the Comprehensive Diagnostic Scale of College Students' Interpersonal Relations, the score of 9-14 shows good interpersonal relationship and general distress), as shown in Table 1. However, according to the questionnaire survey of 747 students from 28 universities conducted by the Social Learning Resources Bureau of the Higher Education Press, 10.1\% of the college students still have serious problems in interpersonal communication, therefore; the interpersonal communication problems of college students cannot be ignored.

In the various dimensions of the interpersonal relationship scale, college students are more puzzled by interpersonal conversation, heterosexual interactions and manner of dealing with people, it shows that college students' interpersonal communication behaviors have different tendencies in the above four dimensions. Therefore, the interpersonal relationship problems of college students must attract the attention of all aspects of society, in particular, universities should put forward effective crisis intervention mode to guide students to learn self-help and other ways to cope with setbacks and crisis and change crisis into opportunities for growth, establish crisis early warning system, and implement active prevention and intervention for early warning targets. 
Table 1. Comparison of mean values of each dimension of interpersonal relationship

\begin{tabular}{cccc} 
variable & $\mathrm{N}$ & Mean & Std. Deviation \\
\hline interpersonal conversation & 1360 & 12.84 & 10.665 \\
interpersonal communication & 1360 & 12.45 & 11.675 \\
behave yourself & 1360 & 8.88 & 6.900 \\
heterosexual contact & 1360 & 10.12 & 7.344 \\
total & 1360 & 11.07 & 9.146 \\
\hline
\end{tabular}

The variance analysis was carried out for students with different disciplines; the specific results are shown in Table 2, the students with different disciplines all have significant differences in the four dimensions of interpersonal relationship. The scores of art students are significantly higher than non-art students in treating people and receiving things; the scores of science students are significantly higher than liberal arts students in interpersonal conversation, and the scores of students in heterosexual communication are significantly higher than science students.

Table 2. Comparison results of differences in dimensions of interpersonal relationships in different discipline

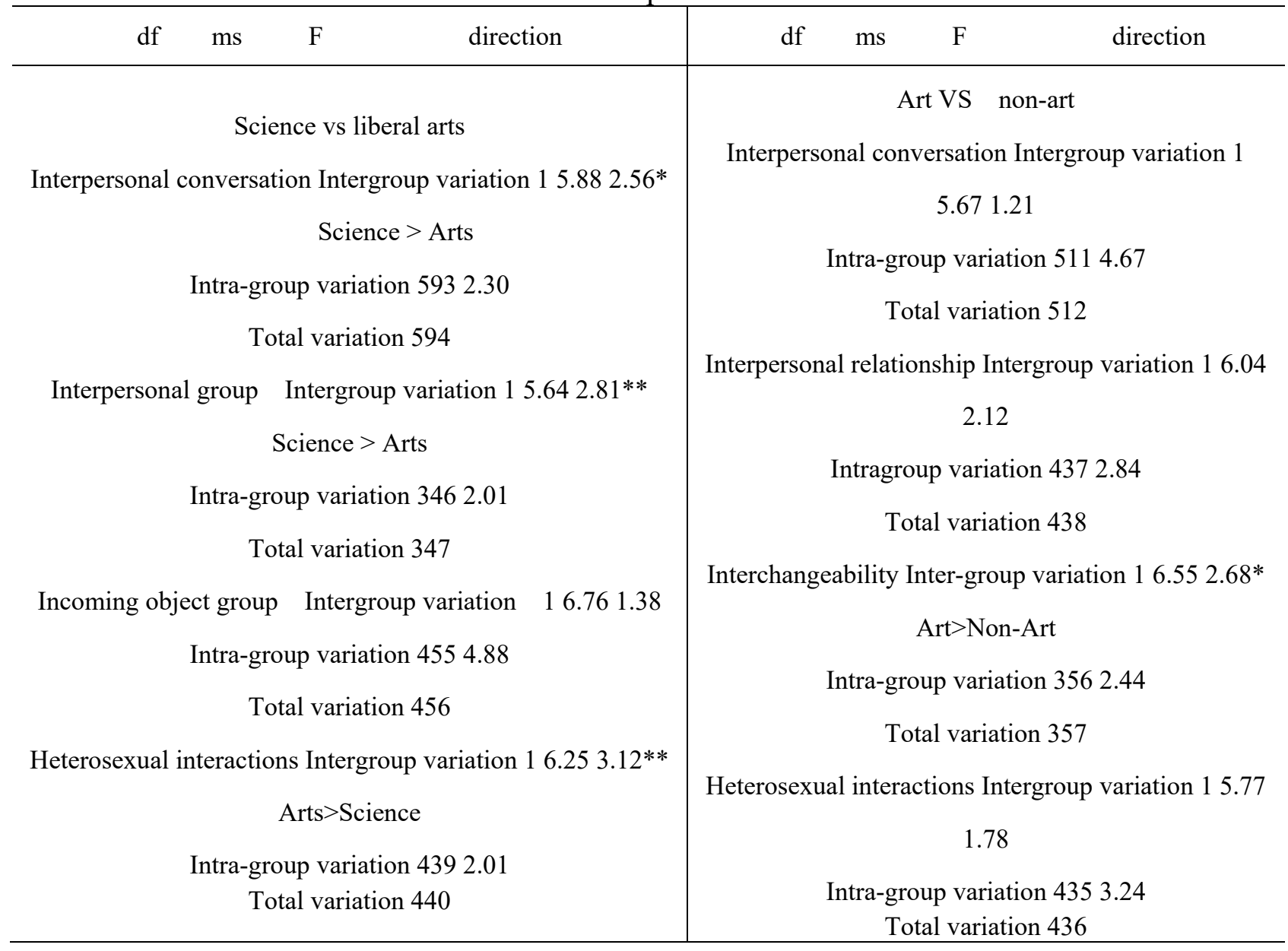

\section{Relationship between Self-consciousness and Interpersonal Relationship}

The relationship of the inner self in self-consciousness, interpersonal conversation in public self and interpersonal relationship, interpersonal communication, personal connection, and heterosexual interaction are shown in Table 3. There are significant correlations in dimensions of selfconsciousness and dimensions of interpersonal relationships. 
Table 3. Correlation between self-consciousness and dimensions of interpersonal relationship

\begin{tabular}{rcccc} 
& $\begin{array}{c}\text { interpersonal } \\
\text { conversation }\end{array}$ & $\begin{array}{c}\text { interpersonal } \\
\text { communication }\end{array}$ & $\begin{array}{c}\text { manner of dealing with } \\
\text { people }\end{array}$ & $\begin{array}{c}\text { heterosexual } \\
\text { interaction }\end{array}$ \\
\hline $\begin{array}{r}\text { inner } \\
\text { self }\end{array}$ & 0.061 & 0.039 & 0.023 & 0.051 \\
public & $0.085^{*}$ & $0.173^{* *}$ & $0.177^{* *}$ & $0.071^{*}$ \\
self & & & & \\
\hline
\end{tabular}

\section{Regression Analysis of Self-consciousness on Interpersonal Relationship}

In order to further investigate the prediction and influence of public self and inner self the two dimensions in self- consciousness on interpersonal relationship, we take the scores of public self and inner self two dimensions as independent variables, and the total scores of interpersonal relationships as dependent variables. The gradual regression analysis was performed; the results are shown in Table 4. The results show that both the public self and the inner self are successfully incorporated into the regression equation model, this result shows that the public self and the inner self in the selfconsciousness have a strong predictive and influential effect on interpersonal relationships.

Table 4. Regression analysis of self-conscious inner self, public self and interpersonal relationship

\begin{tabular}{ccccc}
\hline variable & beta & se & $\beta$ & $\mathrm{t}$ \\
\hline inner self & 0.08 & 0.02 & 0.03 & $2.10^{*}$ \\
public self & 0.06 & 0.02 & 0.07 & $2.07^{*}$ \\
\hline
\end{tabular}

\section{Discussion}

Characteristics of College Students' Interpersonal Relationship

The measurement results show that the overall situation of college students' interpersonal relationship is good, the average score is 11.07 . There is no significant difference with the national college students' norm, but some college students already have serious interpersonal communication problems. This shows that the interpersonal relationship problem of college students cannot be ignored, the students who have interpersonal communication problems, if do not intervene and actively guide, it is likely to cause more serious psychological problems and interfere with the normal life and learning of students, it will leave indelible scars on its future development.

Interpersonal relationships are influenced by various factors, including personal factors, social factors, and family factors. Personal factors include personality, ability, goals, psychological quality, and will. Social factors include economic level, social system, social development trend and social atmosphere; family factors include family harmony, parental education methods, family economic conditions, family care and support and family social relationships.

College students of different schools and disciplines have significant differences in the four dimensions of interpersonal relationships. The scores of normal students are significantly higher than non-normal students in interpersonal communication and heterosexual communication; the scores of art students are significantly higher than those non-art students in manner of dealing with people; the scores of students in private universities are significantly higher than those in public universities, the scores of science students are significantly higher than liberal arts students in interpersonal conversations, the scores of the liberal arts students are significantly higher than the science students in heterosexual interaction, normal students are higher than non- normal students in interpersonal and heterosexual interactions, and it shows that the trouble of interpersonal relationship of normal students is higher than non-normal students. This is likely to be related to the daily education for 
normal students and the requirements of the normal students, because the teacher's "be a model for others" has leave deep imprint on the normal students. They may be more cautious in dealing with people and more cautious when dealing with the opposite sex. Art students have more troubles in dealing with people than non-art students; this is probably related to the characteristics of art majors, art majors do not restrict the personality development, in order to explore the inner art nature of students, as time passes, art students do not consider social approval when behave themselves, but in a unique way, this inevitably creates friction and estrangement with students with different personalities around them. Interestingly, the scores of science students significantly are higher than liberal arts students in interpersonal conversations, the scores of science students are significantly higher than liberal arts students in heterosexual interaction. This may be related to the nature of the discipline, science students form a scientifically rigorous attitude and rational thinking habits in their learning and life, more rigorous, so when talking to people, often talk about some major principles, and argue on the basis of reason, do not consider other people's feelings, thus causing problems in interpersonal communication. The liberal arts students are more emotional, abandon oneself to emotion, and inadvertently hurt others' feelings, but also easy to bring trouble to themselves.

The research results of this paper show that college students with different disciplines and different school are not fully same in interpersonal relationship problems; therefore, intervention methods for different student characteristics are advisable, shoot the arrow at the target, it can more effectively solve the problems existing in the interpersonal relationship of college students in China.

Predictive Analysis of Self- consciousness on Interpersonal Relationship

Through the regression analysis of self-consciousness on interpersonal relationship, we can see that both the inner self and the public self in self-consciousness have a strong predictive effect on interpersonal relationships, some studies have pointed out that only the inner self has a predictive effect on interpersonal relationships. Current research shows that the inner self and the public self all have predictive effects. For this inconsistent result, we speculate that it is likely to be related to the following factors: (1) different samples, due to different sample collections of colleges and universities, in addition to different economic and social factors in various provinces and cities, the impact of college students' self-consciousness and interpersonal relationships may not be the same. (2) Different time, the rapid development of today's social economy may also have a subtle influence on the psychological status of college students, and also suggest that our research on selfconsciousness and interpersonal relationship should take social development as the big background, and Look at this topic from a development perspective.

This research points out that the inner self and the public self in self- consciousness have a strong predictive and influential effect on interpersonal relationships, and this result has a strong practical significance. Self-consciousness is the most basic characteristic of an individual, which directly or indirectly affects the individual's behavior. Through the improvement of college students' selfconsciousness, they can actively and healthily recognize themselves, objectively evaluate themselves, and even can avoid the occurrence of interpersonal relationship problems. High-quality interpersonal relationship is an important feature of college students' mental health, family relationship, peer relationship and teacher-student relationship are the main contents of college students' interpersonal communication network, and have an important impact on college students' self-consciousness.

Therefore, it is necessary to pay attention to the cultivation and correct guidance of college students' self-consciousness, strengthen the mental health education propaganda and psychological counseling services, and eliminate the students' concerns of seeking psychological counseling or crisis intervention, and guide students to learn to cope with setbacks and crisis, change crisis into growth opportunity, establish a crisis early warning system, and implement active prevention and intervention for early warning targets. However, it should be noted that college students with problems should try to avoid the labeling effect as far as possible. The psychological help-seeking attitude refers to the psychological tendency where the objectively psychologically ill-seekers seek help from the powers other than the individual for the purpose of solving the problem or relieving the pain. 


\section{References}

[1]. Guo Cheng. Colleges and Universities Should Strive to Train Qualified Personnel in the New Era, Journal of Chaohu College, 2002(1).

[2]. Wang Xiangdong, Wang Xilin, Ma Hong, etc. Mental Health Rating Scale Manual, Updated version, Beijing: China Mental Health Journal, 1999: 175-189, 241-244.

[3]. Li Rongrong. Research on the Relationship between College Students' Interpersonal Relationship Orientation and Self- consciousness[J]. Psychological Science, 2002, 25(3). 